\title{
ANALISIS PERBEDAAN PENDAPATAN \\ PADA USAHATANI PADI SAWAH DAN PADI RAWA \\ (Suatu Kasus di Desa Sukanagara Kecamatan Lakbok Kabupaten Ciamis)
}

\section{DIFFERENTIAL ANALYSIS OF INCOME IN PADDY AND SWAMP RICE FARMING (A Case in Sukanagara Village, Lakbok District, Ciamis Regency)}

\author{
WIWIT ASRIANI ${ }^{1}{ }^{*}$, TRISNA INSAN NOOR ${ }^{2}$, AGUS YUNIAWAN ISYANTO ${ }^{1}$ \\ ${ }^{1}$ Fakultas Pertanian Universitas Galuh \\ ${ }^{2}$ Fakultas Pertanian Universitas Padjadjaran \\ *E-mail: wiwitasriani10@gmail.com
}

\begin{abstract}
ABSTRAK
Penelitian ini bertujuan untuk mengetahui: (1) Besarnya pendapatan usahatani padi sawah dan rawa di Desa Sukanagara Kecamatan Lakbok Kabupaten Ciamis, dan (2) Perbedaan pendapatan pada usahatani padi sawah dan padi rawa di Desa Sukanagara Kecamatan Lakbok Kabupaten Ciamis. Penelitian dilaksanakan dengan menggunakan metode survei pada Musim Tanam II tahun 2018/2019. Sampel petani padi sawah dan padi rawa ditentukan dengan menggunakan rumus Slovin sehingga diperoleh ukuran sampel petani padi sawah sebanyak 91 orang dan petani padi rawa sebanyak 41 orang. Data yang digunakan terdiri atas data primer dan sekunder. Perbedaan pendapatan usahatani padi sawah dan padi rawa dianalisis dengan menggunakan uji t. Hasil penelitian menunjukkan bahwa: (1) Pendapatan usahatani padi sawah sebesar Rp 13.121.231, sedangkan pada padi rawa sebesar Rp 3.590.732, dan (2) Terdapat perbedaan signifikan pendapatan usahatani padi sawah dan rawa.
\end{abstract}

Kata kunci: perbedaan pendapatan, usahatani, padi sawah, padi rawa

\begin{abstract}
This study aims to determine: (1) The amount of income from paddy and swamp rice farming in Sukanagara Village, Lakbok Subdistrict, Ciamis Regency, and (2) Differences in income in paddy and swamp rice farming in Sukanagara Village, Lakbok Subdistrict, Ciamis Regency. The study was conducted using a survey method in Planting Season II of 2018/2019. The sample of paddy and swamp rice farmers was determined using the Slovin formula to obtain a sample size of 91 paddy rice farmers and 41 swamp rice farmers. The data used consists of primary and secondary data. Differences in income from paddy and swamp rice farming were analyzed using the t test. The results showed that: (1) The income of paddy rice farming was $R p$ 13,121,231, while in swamp rice farming was $R p$ 3,590,732, and (2) There was a significant difference in the income of paddy and swamp rice farming.
\end{abstract}

Keywords: income differences, farming, paddy rice, swamp rice

\section{PENDAHULUAN}

Tanaman padi dapat dibedakan dalam dua tipe, yaitu padi kering yang tumbuh di dataran tinggi dan padi sawah yang memerlukan air menggenang (Kansius dalam Bambang, 2013).
Budidaya padi selain dilaksanakan di lahan sawah, ladang, tegalan juga dapat dilaksanakan di lahan rawa. Menurut data Dinas Pertanian dan Ketahanan Pangan Kabupaten Ciamis (2018), lahan rawa di Kabupaten Ciamis hanya terdapat di Kecamatan Lakbok seluas 5 hektar. 
Sistem budidaya padi pada lahan yang berbeda (sawah dan rawa) akan memerlukan biaya yang berbeda pula. Selain itu, penerimaan dan pendapatan pada budidaya padi di lahan yang berbeda tersebut akan menghasilkan penerimaan dan pendapatan yang berbeda pula.

Penelitian ini dilaksanakan dengan tujuan untuk mengetahui: (1) Besarnya pendapatan usahatani padi sawah dan rawa di Desa Sukanagara Kecamatan Lakbok Kabupaten Ciamis, dan (2) Perbedaan pendapatan pada usahatani padi sawah dan padi rawa di Desa Sukanagara Kecamatan Lakbok Kabupaten Ciamis.

\section{METODE PENELITIAN}

Penelitian dilaksanakan di Desa Sukanagara Kecamatan Lakbok Kabupaten Ciamis pada Musim Tanam II tahun 2018/2019.

Metode penelitian yang digunakan adalah penelitian kuantitatif. Menurut Sugiyono (2017), Penelitian kuantitatif adalah metode penelitian yang dilandaskan pada filsafat positivisme, digunakan untuk meneliti pada populasi atau sampel tertentu, pengumpulan data menggunakan instrument penelitian, analisis data bersifat kuantitatif atau statistik, dengan tujuan untuk menguji hipotesis yang telah ditetapkan.
Jenis penelitian yang digunakan dalam penelitian ini adalah survai di Kabupaten Ciamis. Menurut Nazir (2014), metode survai merupakan penyelidikan yang diadakan untuk memperoleh faktafakta dari gejala-gejala yang ada dan mencari keterangan-keterangan secara faktual, baik tentang institusi sosial, ekonomi, ata politik dari suatu kelompok ataupun suatu daerah. Metode survai dilakukan di lapangan, karena desain untuk penelitian survai sangat bergantung dari pemilihan responden, pemilihan alat mengumpulkan data, prosedur yang dilaksanakan serta kondisi di lapangan.

Data yang digunakan meliputi data primer dan sekunder. Menurut Sanusi (2012), data primer ialah data yang pertama kali dicatat dan diperoleh langsung dari sumber aslinya dengan tujuan tertentu. Data primer diperoleh secara langsung dari petani dan dilakukan melalui wawancara langsung dengan responden menggunakan kuesioner yang telah dipersiapkan terlebih dahulu. Sedangkan data sekunder ialah data yang sudah tersedia dan dikumpulkan oleh pihak lain di luar instansi yang diteliti. Pengumpulan data sekunder dilakukan melalui studi pustaka dan kunjungan ke dinas atau instansi terkait pada penelitian ini. 
Petani padi di lahan sawah sebanyak 1.015 orang, sedangkan petani padi di lahan rawa sebanyak 70 orang. Penarikan sampel petani padi sawah dan rawa dilakukan dengan menggunakan rumus Slovin dengan menggunakan tingkat kesalahan (e) sebesar 10\% sehingga diperoleh ukuran sampel petani padi sawah sebanyak 91 orang, sedangkan petani padi rawa sebanyak 41 orang. Pengambilan sampel dilakukan dengan simple random sampling. Menurut Arikunto (2010), simple random sampling adalah teknik penarikan sampel dengan cara peneliti mencampur subyek-subyek di dalam populasi sehingga semua subyek dianggap sama.

Biaya total (Total Cost) diperoleh dengan cara menjumlahkan biaya tetap total (Total Fixed Cost) dengan biaya variabel total (Total Variable Cost) dengan rumus sebagai berikut Suratiyah (2006):

$\mathrm{TC}=\mathrm{TFC}+\mathrm{TVC}$

Dimana:

$\mathrm{TC}=$ Total cost (biaya total)

$\mathrm{TFC}=$ Total Fixed Cost (biaya tetap total)

TVC $=$ Total Variable Cost (biaya variabel total)

Penerimaan dihitung dengan menggunakan rumus menurut Soekartawi (2002) sebagai berikut:

$\mathrm{TR}=\mathrm{Q} . \mathrm{P}$

Dimana:
$\mathrm{TR}=$ Total Revenue (penerimaan total)

$\mathrm{Q}=$ Quantity (volume penjualan)

$\mathrm{P}=$ Price (Harga jual)

Pendapatan adalah penerimaan total (Total Revenue/TR) dikurangi dengan biaya total (Total Cost/TC), dan dihitung dengan menggunakan rumus menurut Suratiyah (2006) sebagai berikut:

$\pi=\mathrm{TR}-\mathrm{TC}$

Dimana:

$\pi=$ Pendapatan

$\mathrm{TR}=$ Total Revenue (penerimaan total)

$\mathrm{TC}=$ Total cost (biaya total)

Perbedaan pendapatan usahatani padi sawah dan rawa diuji dengan menggunakan uji t tidak berpasangan (non paired t-test). Menurut Ghozali (2012), analisis uji beda membandingkan rata-rata dua grup yang tidak berhubungan satu dengan yang lain. Apakah kedua grup tersebut mempunyai nilai rata-rata yang sama ataukah tidak sama secara signifikan. Dinyatakan dengan rumus sebagai berikut:

Dimana:

$$
\mathrm{t}=\frac{\bar{X}_{1}-\bar{X}_{2}}{\sqrt{\frac{s_{1}^{2}}{n_{1}}+\frac{s_{2}^{2}}{n_{2}}}}
$$

$\bar{X} 1=$ rata-rata sampel kesatu

$\bar{X} 2=$ rata-rata sampel kedua

$S_{1}=$ varian kelompok kesatu

$S_{2}=$ varian kelompok kedua

$n_{1}=$ banyak subjek kelompok kesatu

$n_{2}=$ banyak subjek kelompok kedua

Hipotesis: 
- $\mathrm{H}_{0}=$ Tidak terdapat perbedaan pendapatan antara usahatani padi sawah dan padi rawa

- $\mathrm{H}_{1}=$ Terdapat perbedaan pendapatan antara usahatani padi sawah dan padi rawa

Kaidah keputusan:

- Jika t-hitung $\leq$ t-tabel, maka $\mathrm{H}_{0}$ diterima

- Jika t-hitung > t-tabel, maka $\mathrm{H}_{0}$ ditolak

\section{HASIL DAN PEMBAHASAN}

\section{Identitas Responden}

Petani padi sawah sebagian besar (85,71\%) berusia produktif (15-64 tahun), sedangkan petani padi rawa sebanyak $82,93 \%$. Petani padi sawah sebagian besar (64\%) berpendidikan sekolah dasar (SD), sedangkan petani padi rawa $90 \%$. Sebagian besar petani padi sawah (76\%) memiliki tanggungan keluarga sebanyak 1-3 orang, sedangkan $78,05 \%$ petani padi rawa memiliki tanggungan keluarga lebih dari 3 orang.
Sebagian besar $(58 \%)$ petani padi sawah memiliki pengalaman dalam berusahatani padi selama 5-25 tahun, sedangkan petani padi rawa sebanyak $56 \%$. Sebagian besar petani padi sawah $(65,93 \%)$ memiliki lahan usahatani padi seluas lebih dari 0,25 ha, sedangkan $80,49 \%$ petani padi rawa memiliki lahan usahatani padi seluas kurang dari 0,25 ha.

\section{Pendapatan Usahatani}

Pendapatan merupakan selisih antara penerimaan dengan biaya. Analisis biaya, penerimaan dan pendapatan usahatani padi sawah dan padi rawa pada MT II tahun 2018/2019 dapat dilihat pada Tabel 1.

Tabel 1 menunjukan bahwa biaya tetap total yang dikeluarkan pada usahatani padi sawah dan padi rawa pada MT II 2018/2019 tidak jauh berbeda karena biaya $\mathrm{PBB}$, penyusutan alat, dan bunga modal relatif sama. 
Tabel 1. Biaya, Penerimaan, Pendapatan Usahatani Padi Sawah dan Padi Rawa MT II 2018/2019

\begin{tabular}{|c|c|c|c|c|c|}
\hline & \multirow{3}{*}{ Uraian } & \multicolumn{4}{|c|}{ Musim Tanam II } \\
\hline & & \multicolumn{2}{|c|}{ Lahan Sawah } & \multicolumn{2}{|c|}{ Lahan Rawa } \\
\hline & & Jumlah & $\%$ & Jumlah & $\%$ \\
\hline \multirow[t]{5}{*}{ A } & Biaya Tetap & & & & \\
\hline & 1. $\mathrm{PBB}(\mathrm{Rp})$ & $200.000,00$ & 16 & $125.227,273$ & 11 \\
\hline & 2. Penyusutan Alat (Rp) & $699.365,71$ & 57 & $666.084,15$ & 58 \\
\hline & 3. Bunga Modal (Rp) & $325.674,81$ & 27 & $363.616,05$ & 31 \\
\hline & Biaya Tetap Total (Rp) & $1.225 .040,52$ & 100 & $1.154 .927,46$ & 100 \\
\hline \multirow[t]{8}{*}{ B } & Biaya Variabel & & & & \\
\hline & 1. Sarana Produksi & & & & \\
\hline & a. Benih (Rp) & $226.225,77$ & 3 & $232.363,64$ & 6 \\
\hline & b. Pupuk Organik (Rp) & $181.081,39$ & 3 & $662.307,69$ & 18 \\
\hline & c. Pupuk Kimia (Rp) & $1.533 .543,71$ & 22 & $1.854 .774,13$ & 50 \\
\hline & d. Pestisida (Rp) & $142.677,31$ & 2 & $720.403,72$ & 19 \\
\hline & 2. Tenaga Kerja (Rp) & 4.966.180,16 & 70 & 5.962 .727 & 7 \\
\hline & Biaya Variabel Total (Rp) & $7.049 .708,35$ & 100 & $9.432 .576,18$ & 100 \\
\hline $\mathrm{C}$ & Biaya Total $(\mathrm{Rp})$ & $8.274 .748,87$ & & $10.587 .503,64$ & \\
\hline \multirow[t]{4}{*}{$\mathrm{D}$} & Penerimaan & & & & \\
\hline & Produksi (kg) & 4.875 & & $3.358,18$ & \\
\hline & $\operatorname{Harga}(\mathrm{Rp} / \mathrm{kg})$ & 4.200 & & 4.222 & \\
\hline & Penerimaan Total (Rp) & 20.358 .449 & & 14.178 .236 & \\
\hline $\mathrm{E}$ & Pendapatan (Rp) & 13.121 .231 & & 3.590 .732 & \\
\hline
\end{tabular}

\section{Perbedaan Pendapatan}

Perbedaan pendapatan usahatani padi di lahan sawah dan rawa diuji dengan menggunakan uji t dengan menggunakan SPSS, sebagaimana dapat dilihat pada Tabel 2.

Tabel 2. Uji Perbedaan Pendapatan

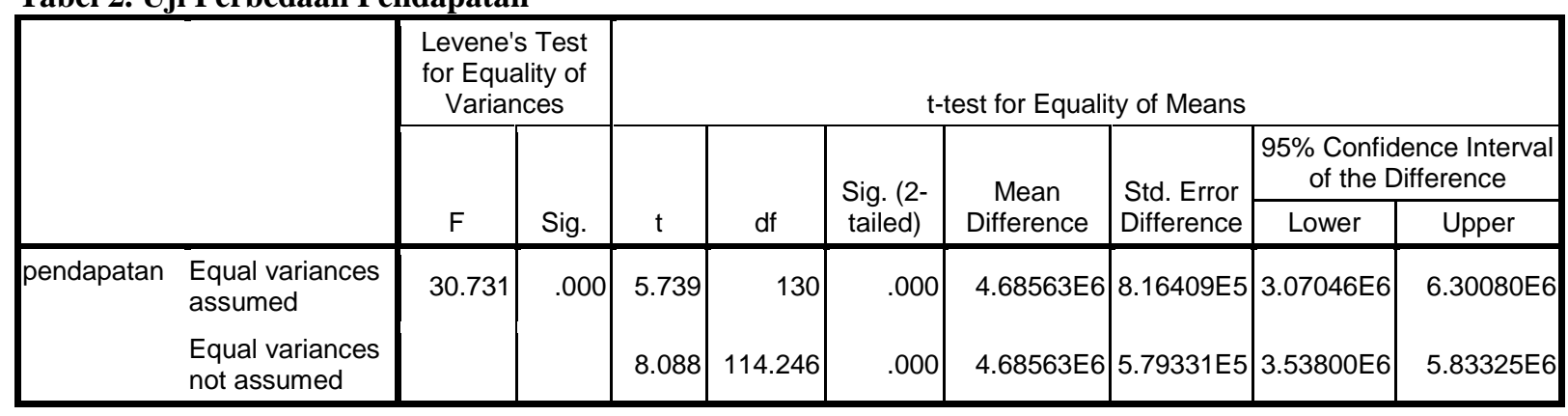

Tabel 2 menunjukkan nilai signifikansi sebesar $0,000<0,005$ sehingga dapat disimpulkan terdapat perbedaan yang signifikan antara pendapatan usahatani padi di lahan sawah dan rawa.

\section{KESIMPULAN DAN SARAN}

\section{Kesimpulan}

1. Pendapatan usahatani padi sawah sebesar Rp 13.121.231, sedangkan pada padi rawa sebesar Rp 3.590.732.

2. Terdapat perbedaan signifikan pendapatan usahatani padi sawah dan rawa. 


\section{Saran}

Peningkatan produksi dan pengoptimalan penggunaan faktor-faktor produksi untuk meningkatkan pendapatan petani, baik di lahan sawah maupun rawa.

\section{DAFTAR PUSTAKA}

Arikunto, S. 2010. Prosedur Penelitian Suatu Pendekatan Praktik. Edisi Revisi 2010. Rineka Cipta. Jakarta.

Dinas Pertanian dan Ketahanan Pangan Kabupaten Ciamis. 2018. Data Tanam, Panen, Produksi dan Produktifitas Padi Kabupaten Ciamis. Laporan Tahunan 2018. Ciamis.
Ghozali, I. 2012. Aplikasi Analisis Multivariate dengan Program IBM SPSS. Semarang: Universitas Diponegoro.

Nazir, M. 2014. Metode Penelitian Survai. Bogor: Ghalia Indonesia.

Rodjak, A. 2006. Manajemen Usahatani. Pustaka Giratuna Bandung Fakultas Pertanian Universitas Padjajaran. Bandung.

Sanusi, A. 2012. Metode Penelitian Bisnis. Jakarta: Salemba Empat.

Soekartawi. 2002. Prinsip Dasar Ekonomi Pertanian, Teori dan Aplikasi. Jakarta: PT. Raja Grafindo Persada.

Sugiyono. 2017. Metode Penelitian Kantitatif, Kualitatif, dan $R \& D$. Bandung: Alfabeta.

Suratiyah, K. 2006. Pengembangan Ilmu Usahatani. Jakarta: Penebar Swadaya. 